\title{
Lapurdum
}

Euskal ikerketen aldizkaria | Revue d'études basques |

Revista de estudios vascos | Basque studies review

4 | 1999

Numéro IV

\section{Euskarazko irakaskintzaren historia ororen eskolen ildotik, iraultzaren frantses garaiko eskola liburuxka bat}

\section{Bernard Oyharçabal}

\section{(2) OpenEdition}

1 Journals

\section{Édition électronique}

URL : http://journals.openedition.org/lapurdum/1545

DOI : 10.4000/lapurdum.1545

ISSN : 1965-0655

Éditeur

IKER

\section{Édition imprimée}

Date de publication : 1 octobre 1999

Pagination : 81-105

ISBN : 2-84127-156-0

ISSN : 1273-3830

Référence électronique

Bernard Oyharçabal, «Euskarazko irakaskintzaren historia ororen eskolen ildotik, iraultzaren frantses garaiko eskola liburuxka bat », Lapurdum [Linean], 4 | 1999, Sarean emana----an 01 avril 2010,

kontsultatu 31 janvier 2020. URL : http://journals.openedition.org/lapurdum/1545; DOI : 10.4000/ lapurdum. 1545 


\section{B. OYHARÇABAL}

\section{EUSKARAZKO IRAKASKINTZAREN HISTORIA OROREN ESKOLEN ILDOTIK, IRAULTZAREN FRANTSES GARAIKO ESKOLA LIBURUXKA BAT}

Artikulu honek bi helburu ditu : lehenbizikorik ezagutzera ematea katixima hutsa ez den euskarazko eskola-liburuxka bat, duela berrehun bat urte egina, erran nahi baitu, segurenaz ere, dugun dokumentazio urri baino urriagoaren arabera mota horretako testurik zaharrena; bigarrenekorik, agerian ezartzea 19. mendea arte izan zela Iparraldeko eskola herrikoietan euskarazko irakaskintza bat, maila apalekoa, eta alde horretarik orain jendarteratzen dugun irarlan hau, zenbait alderditarik aro berriagoen seinaleak ere dauzkan arren, eskola tradizio zaharrago horri darraion zerbait dela.

Lehenbiziko partean Iraultza aitzineko Iparraldeko ororen eskolez hitz bat erranen dugu, haiei esker bereziki izan baitzen 17 eta 18. mendeetan idatziaren gainean finkatua zen euskarazko ekoizpen bat, behe mailako gizarte-taldeentzat egina. Belapeyrek utzi digun lekukotasuna baliatuz bereziki, eskola horietaz zenbait informazio eman ondoan, haien helburuez eta eraginaz ariko gara. Bigarren partean Instructionea, gazteriarentçat eta Haurren instructionea deitu bi idazkien ezaugarri nabarienak agerraraziko ditugu, eta ondotik testua eskainiko.

\section{Iparraldeko ororen eskolak 19. menderaino.}

Nahiz Euskal Herriko historia ikertzen duten liburuetan ez diren biziki aipatzen, izan ziren 17. mendean, eta are gehiago, 18. mendean, Iparraldeko euskal herrialdeetan, erresumako beste aurkientzetan bezala, hala nola Biarnon' eta Baionan ${ }^{2}$, Frantzian petites écoles erraten zitzaien, eta euskaraz Belapeyrek ororen eskola deitu zituen eskolak. Egitura horiek, maiz herriek berek antolatzen bazituzten ere, eta erregeek, 1698 tik aitzina oroz gainetik ${ }^{3}$, sustatzen, elizak bultzatu zituen, Trentoko kontzilioaren ondotik bereziki ${ }^{4}$, bere irakaskintza jendeen artean hobeki finkatzeko. Elizaren erakundeetarik kanpo izanagatik askotan, batez ere herri gotorretan, elizako buruzagiek begipean zeuzkaten, eta apezpikuak parropietan egiten zituen bisitetan, hori zen behatzen zien puntuetarik bat, hots, ea eskolatze hori egiten ote zen egiazki, eta parropiako errejenta elizako buruzagiek onartu ote zuten. Euskaraz egina zen eskolatze hori Euskal Herrian, bai Baionako diosesan, bai Oloroekoan eta Akizekoan ${ }^{5}$.

Antolamendu horren berri ematen digute aski garbiki Belapeyrek bere katiximaren (1696) atarian argitara eman zituen hiru dokumentuk. Lehenbiziko biak frantsesez dira, hirugarrena euskaraz. 
Lehena da ordenantza bat (27/07/1693), Belapeyrek, $\mathrm{C}<\mathrm{h}>$ amalbidek eta de Bisqueyk izenpetua, hartan, aitzineko legezko oinarriak gogoratu ondoan, hauxe jakinarazten baita : Nous avons ordonné, au conformément au susd arrêt du Conseil d'Etat du 18 septembre 1665 tous les curés du présent païs de Soule, feront incessamment établir chacun en droit-soy, par la voye du droit, un ou deus Régens d'école, de la qualité requise, selon la portée, \& situation de leurs paroisses, pour l'instruction \& éducation des enfans dans la crainte de Dieu, \& la connoissance de ses saints mystères, compris au catéchisme du présent diocèse, que nous avons composé en langue basque, vulgaire du présent païs, au dépens de chaque communauté.

Bigarrena beste ordenantza bat da, 1695ekoa, Lextarreko jujeei Chamalbide, Zuberoan Promotoraren ordaina zenak adierazia. Hemen gorago aipatu ordenantza berriz hartzen du, eta zehazten du nork pagatu beharko duen irakaskintza, dioelarik: Il vous plaise de vos graces, ordonner à tous les jurats députés, \& à leur défaillance, aux margilliers des grandes cuvres de chaque paroisse du présent païs de Soule, \& ainsi députés nés d'ancienneté desd. Paroisses, de faire établir \& gager incessamment des maîtres des petites écoles, \& même des maitresses s'il est possible, les tous de la qualité requise, \& dans la forme telle que de droit, sur tous les contribuables de leur communautés, lequels elles entretiendront continuellement \& à perpétuité par les voyes convenables qu'ils aviseront.

Hirugarrena euskaraz egin ordenantza da, Belapeyrek Zuberoako ofizial gisa Zuberoako erretor eta bikariei manatua. Aitzinean aipatu dokumentuetan oinarriturik, adierazten die nola joka. Katiximaren irakasteko eta ororen eskolak sortzeko beharraz ari izan ondoan, galdegiten die apaizei eta bikarioei, edo berek sortzeko eskola hori, baldin beste lanek astirik uzten badie, edo bestela eginarazteko, horretarako elizako buruzagiek onetsi bizitze oneko norbait hautaturik : Erretor eta Vicariec biciki escola eraciren dutie bere Parropietaco haur gaztiac, chipiçaroan hiki ikhas, eta hartia hobeki bethicoz beguiratcen ahal dielacoz. Hala goure Jaun Apezcupiaren ordenancen arau, Norc bere Parropietan, Ororen escolabat eçar eraciren die ahalic sarriena, çognez arrancura berhecibat Vkenen baitie bere erretorietaco eguinbidec lekhu derieno, auher eztaudian, nontic sortcen huitira vicioac, edo beste escola burçagui onsa ikhassi, bicitce honetaco, eliçaco javez onhexi datian, bati eraguinen. Halaber, neska-eskola, ahalaz bereiz, eragin dezaten eskatzen die Belapeyrek erretoreei, parropiak ordaindu emazte bat emanez errejent gisa : Baita ahalaz eçariren berhez nescatilen, serora edo beste burçaguissa berhalacoac : çoin saristatu baitirate Parropiaz, goure erregue Jaunaren, haren Conseilluco, eta Intandanten erregla honen arau.

Eskola horren ibilera segitu beharko dute erretoreek, eta parropia tipienetan aski indarrik ez bada errejent baten izateko, elkarretaraziko ditu haurrak : Erretorec ardura ikhoussiren dutie escolac, iaquiteco erregentac bere eguinbidetan diratianez. Eta Parropia chipiec ezpadie indar aski erregent bederaren etchequiteco, eliçaco Guehienez lagunturic, hourac algargana eraciren dutie, ororen gain arteco erregent baten eçarteco.

Irakaskintza hori urte guztian emateko izanen da, salbu, lur lanengatik, uztailabuztuetan eta urrian : Azkenecoz Çuberoa herri hontaco Promotora manatcen dugu, iratçarriki orotan valia eraci deçan legue haur, bestela honen hauxliac gaz- 
tigatu içanen dira cinez khorte espiritualian : Salbu uztailla, Agorrila, urrieta hilabetetan, noiz baitira lur lanen lehia bicigarriac.

Azkenik, herritar guztiek ordenantzaren berri izan dezaten eta ahantz ez dezaten galdatzen die erretoreei, urtean bi aldiz ordenantza irakurtzeko elizetan : Eta hobeki oro eguinbide honçaz orhit ditian, erretorec ourthecal Pronoaren ondoan, Ordenança haur goraki iracourturen die domi seinthoreren bi ondoco lehen igantetan.

\section{Ororen eskolen egitekoa.}

Erran gabe doa irakaskintza honen sortzeko lehen arrazoia katiximaren ikasaraztea izan zela. 1739.ean argirata eman zen Méthode familière pour les petites écoles erraten da : la lecture et l'écriture [...] ne doivent être regardées que comme accessoires et comme des moyens qui conduisent à cette fin. (Croix \& Quiénart, $1998: 336$ )

Hala dio Belapeyrek ere Euskal Herrian, eta horregatik hain zuzen egin zuen euskarazko katixima : Erregentec astecal haurrer eracaxiric, Igantian erran behar dukeyen catechima, bethi lagunturen dutie hartara, hayen gogoz onsa erraitera urgazteco. Eta houra erran urhentu datianian, bere Igante segnharatien arau, berriz has eraciren derie, aski iakinsu diratiano. Ikus daitekeenaz, eskoletako errejentek haurrak katiximaren ikastera lagundu behar zituzten, eta elizara eraman (erretoreen kontrolaren errazteko gisan dudarik batere gabe).

Lapurdin ere, berdintsu ziratekeen gauzak : 1747an, apezpikuaren bisitaren ondotik Miarritzeko parropiaz egin zen erreportean agertzen da ohar bat, zuzentzeko den makur gisa aurkeztua, baizik eta igande eta besta egunetan errejentek ikasleak elizara eramaten ez zituztela (Haristoy, 1890-91 : 22).

Erlijioari zetxizkion egitekoen lehentasuna erakusten du halaber, 1703an apezpikuak egin bisitaren ondoko erreportaren arabera Behorlegin gertatuak: herritarrek eskaturik, manua eman zuen apezpikuak ordu arte eskola baten atxikitzeko enplegatzen zen dirua handik aitzina apaiz bati ordain zekion goizeko meza emateko (Haristoy 1890-91:06).

Halere eskolatzearen bestelako ondorioak ere kontuan hartzen dira. Belapeyrek, adibidez, erretoreei azpimarratzen die haurren eskolara etorrarazteko komeni izanen dela gurasoei esplikatzea haientzăt ere probetxugarri izanen dela haurren eskolaraztea, batetik haien jakitateaz baliatzen ahalko baitira, eta manukorragoak izanen baitira : Orano erretorec eçagut eraciren derie aita amer, burçagui burçaguisser bere haur eta cerbutchariac onsa escola eraciten badutie, lehenic hayen iakitiaren frutia berec goçaturen diela; ceren Gincoaren leguiac ikhassiric, haren cerbutchari hobe baitirate, hanbatenaz emiago eta bere peco baitutukie. (Belapeyre 1696)

Pentsa daiteke zenbait kasutan, herri tarroenetan bereziki, errejentei katiximaz landa besterik ere irakastea eskatzen zitzaiela errejentei. Errejenten eginbideak zehaztean azpimarratzen du Zuberoako ofizialak erlijio irakaspenak izan behar duela lehentasuna eta ez letren ikasketak: qu'en toutes choses, ils [errejentek] travaillent avec plus de soin à leur [ikasleen] avancement spirituel, qu'à l'étude des lettres (1693ko maiatzaren $27 \mathrm{ko}$ ordenantza). 
Badirudi, halere, batzuetan bederen elizarekilako lokarriak laxoago zirela. Apezpikuek, adibidez, behin eta berriz diote errejentak han edo hor ez direla onetsiak izan, horrek adierazten baitu errejenta, erretoreari erran gabe, edo bederen honek onetsi gabe, hauta zezaketela. Baionako apezpikuak 1737 an egin zuen itzulian hogei bat herritan bederen baziren onespenik gabe zeuden errejentak Lapurdin : Aiherran, Angelun, Arruntzan, Bastidan, Basusarrin, Beskoitzen, Bidarten, Donibane Lohizunen, Hiriburun, Kanbon, Itsasun, Larresoron, Makean, Miarritzen, Mugerren, Senperen, Urketan, Urruñan, Uztaritzen, Zubernoan.

Menturaz Zuberoan izan zuten eskola horiek eliza gizonen aldera askatasun gehienik : han bakarrik aurkitu dira, J. Egiategiren idazkiekin, errejent haiek utzi idazlan zenbait, eta han bakarrik sortu da, dudarik batere gabe eskola horiei zerbait gisaz zor zaien kulturazko ekoizpen bat, aipatu nahi baititugu Zuberoako trajeriak edo pastoralak, errejentek sorrarazi eta biziarazi zituztenak.

\section{Ororen eskolen eragina.}

Guti ezagutzen ditugu, oinarrizko irakaskintza oroganatzen hasi baino lehenagoko garaistan, hain urrun ez ditugun 17 eta 18. mendeetan, izan ziren eskola horiek, euskal herrialdeetan, Iparraldeko herri gehienetan bederen, euskaraz egiten zirenak, eta gisa batez cuskarazko irakaskintzari lehen urratsak eginarazi zizkiotenak.

Erresuman molde desberdinetan egin zen eskolatze herrikoi hori. Frantziako iparraldeko eta ekialdeko parteetan franko aitzinatua izan zen, anitzez gutiago berriz hegoaldeko parteetan, salbu Biarnon. Eskolak hiru maila zituen bata bestearen ondotik iragan behar zirnak : lehena zen irakurtzea, bigarrena idaztea, eta hirugarrena kalkulatzea. Haurrek maila horien arabera ordaindu behar zuten eskolatzea : dans la hiérarchie des matières choisies et payées l'arithmétique ou l'art de chiffrer coute toujours deux ou trois fois plus que l'écriture, et l'apprentissage de la lecture représente le premier niveau d'enseignement. (Butel et Manton $1977: 27)^{6}$

Horregatik ongi bereizi behar dira elkarretarik eskolatzea eta alfabetatzea (alfabetatze osoa bederen) : La dissociation entre la lecture et l'écriture représente un fait essentiel de la scolarisation dans la période moderne. Cette dissociation vient réduire singulièrement la portée de la scolarisation, empêchant la majorité des enfants qui fréquentent l'école d'accéder au niveau de l'écriture. (Butel et Manton 1977 : 29)

Ez da erraz oinarrizko irakaskintza horren eragina eta ekarria neurtzea. Jendeen idatziari buruzko gaitasuna izartzeko, baliatu ohi den irizpidea ezkontzetako agirietako ezkonlagunen siñaduretan oinarritzen da : honenbestetarik zenbatek izenpetzen duten ikusiz, estatistikak egiten dira eta horren arabera izartzen da idatziari buruzko gaitasuna. Irizpide horri kritikak egin zaizkio, baina besterik ez delarik, zerbait ideia ematen du gauzak nolatsu ziratekeen. Are gehiago joan den mendean eginikako inkesten balioa berretsi dute berrikitanago egin azterketek (ik. bereziki Fleury \& Valmary 1957 : 71-92), halako gisaz non historialariek baitiote izenpetzeek ongi erakusten dutela alfabetatze osoaren heina ${ }^{7}$. 
Lapurdiren kasuan (Baiona kontuan ez harturik ${ }^{8}$ ) ezagutzen ditugun ikerketen arabera badirudi 18. mendearen hondar partean, Luis XVIaren erregearen denboran, espos lagunetan laurdenek, herenek premuen artean, bazekitela izenpetzen (Lafourcade 1978 : 514). J. Pontet-Fourmiguék bere tesian (1990 : 537) Lapurdiko, Donibane Garaziko eta Donapaleuko aipatzen dituenak itxura berekoak dira, nahiz agerian ematen duen alde handiak izan zitezkeela herri batetik bestera, eta herri batean gizarte taldeen arabera ${ }^{9}$. Historialariek azpimarratu dute toki anitzetan bi aldakik zutela eraginik handiena alfabetatze mailan : hiri izateak (eta orokorkiago, bas-herrietan, etxeak elkarri hurbil jarriak edo bilduak izateak, ik. Muchenbled (1990 : 139), eta sexuak, anitzez apalagoa baita emazteen artean alfabetatuen portzentaia, hirietarik kanpo oroz gainetik.

Ikerketa lanek (ik. bereziki Butel \& Mandon 1977, eta Poussou 1977) erakustera ematen dute aitzinamendu handia zutela Frantziako hegoaldeko herrialdeen artean, Pirinio Apaletako gizonezkoek alfabetatze kontuetan garai haietan. Ordea, ez gaitezke horietan geldi euskal probintzietan gauzak nola ziren jakiteko, zeren departamenduaren barnean, alde handia baitzen Euskal Herriko eta Biarnoko egoeren artean, bereziki, kasu honetan komeni den bezala, Baiona aparte uzten bada.

Halere, gogoan izanik izkirioak ariketa gisa dituen berezitasunak eta ororen eskoletako mailakatzea, pentsa dezakegu irakurtzeko gaitasuna siñadurak zenbatuz lortzen diren portzentaiek adierazten duten baino doi bat handiagoa zela. Alabaina, garai haietan elizaren irakaspenaren bidez egiten den eskolatzeak irakurketa baino urrunago joatea ez du eskatzen jende gehienen kasuan : Celle-ci [siñatzeko gaitasuna] représente un stade intermédiaire entre les niveaux de la lecture et de l'écriture; les générations passées par l'école primaire aquitaine comme par l'école primaire bretonne au XVIII siècle sont dans leur majorité des générations de lisants qui ne se servent pas de l'écrit diote Butel eta Mantonek (1977 : 29) ${ }^{10}$. Frantziako kultura historia ikertu duten bi autorek (Croix et Quiénart 1998: 333) ${ }^{11}$ ber gisan diote : celle-ci [erlijio irakaskintza] inspire une alphabétisation pratiquement limitée à la lecture, qui s'affirmera davantage au XVIIIe siècle, lorsque les effets de la Réforme catholique se seront fait complètement sentir. Alabaina, Furet eta Ozoufek (1977 : 200) dioten bezala, irakurketa eta idazketaren artean egiten zen diferentzia garai haietan erlijio irakaskintzak esplikatzen du oroz gainetik, pedagogia kontuek edo ikasketen kostuak baino gehiago : le fossé entre le sacré et le profane est à l'origine du cloisonnement des deux savoirs.

\section{Ororen eskolen zabalkundea.}

Noiz non egin ziren ororen eskolak ? Zuberoan, Belapeyrek dioenaz, 17. mendearen bukaeran guti zabalduak ziren ororen eskolak ${ }^{12}$. Honela dio 1693 ko maiatzaren $27 \mathrm{ko}$ ordenantzak : Néammoins, par une négligence criminelle, la pluspart des Curés dudit païs obmettent toujours de répandre ces consolations salutaires à leurs peuples, parce qu'ils n'ont jamais eu le soin de faire établir des Maîtres d'école dans leurs paroisses.

Lapurdiko eta Baxenabarreko herrietan ere izan ziren ororen eskolak, segurenaz ere hiri handienetan bederen lehenagotik hasiak. Egia da aski berant agertzen direla lehen aipamen zuzenak. Adibidez, Donibane Lohizunen herriak ordaindu 
errejenten lehenbiziko aipamena 1676ko dokumentu batean kausitzen da (Nogaret $1925: 106)^{13}$. Erran gabe doa horrek ez duela erran nahi deusik ez zela izan aitzinetik, alde batetik aurreko garaietako dokumentazio zahar anitz galdu izan baita, eta bestetik errejent pribatuak baitziratekeen lehenago, ikasleek pagatuak. Horren froga kausitzen dugu Materrek eta Axularrek ekartzen diguten lekukotasunetan, biek baitiote bazirela 17. mendearen lehen partean Lapurdin euskara baizik ez zekiten irakurleak, letratu handiak ez zirenak (erran nahi baitu latin guti zekitenak). Garai haietako bazter hauetako historia guztiz landugabea dugularik, are berantagokoak ditugu (18. mendearen hastapenekoak) Lapurdiko eta Baxenabarreko herrietan ororen eskolez egiten diren lehen aipamen ezagunak, apezpikuen bisiten ondotik egiten ziren erreportetan kausitzen direnak. Haristoyk (1890-91) bisita haietaz egin bilduma ikusiz, erran dezakegu 1703an eskolak bazirela Behorlegi eta Donostiri bezalako herri tikietan, eta, $1737 \mathrm{an}^{14}$, berriz, Angelun, Miarritzen (bi errejent bederen), Bidarten (errejent bat eta bi errejentsa), Arruntzan, Uztaritzen, Mugerren, Urketan, Bastidan, Aiherran, Makean, Itsasun, Kanbon ${ }^{15}$, Larresoron, Senperen ${ }^{16}$, Urruñan, Hendaian, Zubernoan, Donibane Lohizunen, Ziburun, Hiriburun.

Iduri du beraz aski zabalduak zirela ororen eskolak Euskal Herrian. Alfabetatze maila aski apala agertzen bada (Biarnori eta Baionari konparatuz ${ }^{17}$ ), eskola horien ezaugarriengatik dateke. Dokumentazioaren eskasiaren gatik ezaugarri horien segurki ematea neke bada ere, uste dut zenbait puntu aitzina ditzakegun : i) katiximaren irakasteari lotuak ziren oroz gainetik eta horregatik irakurketa zen haurrei eskaini nahi zien oinarrizko irakaskintza (haur askorentzat bakarra, bereziki laborari familietakoen kasuan); ii) katixima euskaraz egina izanik, irakurketaren oinarriak ere hain segur euskaraz finkatzen ziren; iii) irakasleen maila hala-holakoa zen, lanbide aski gaizki ordaindua baitzatekeen ; iv) mutikoentzako eskola zen gehiago neskentzakoa baino, hirietarik kanpo bereziki ${ }^{18}$.

Eskola horiek ez ziren jakintza eskolak, eta gutik ikasten bide zuten haietan jakintzako bideak irekitzen zuten frantsesa eta are gutiago latina. Horrela ulertu behar dira, ene ustez, Garatek gutun batzuetan egin zenbait ohar : les pauvres basques sont pauvres à un tel point qu'il n'y a presque pas de famille où l'on puisse faire un prêtre, un avocat, un médecin parce que le pays n'a aucune école où l'on enseigne autre chose qu'à lire et à écrire (Duhart $1994: 166)^{19}$

\section{Instrukzionea gazteriarentzat.}

Ororen eskoletako irakaskintza nahi izan dut piska bat gogoratu hemen, zeren uste baitut beharrezkoa dela aitzineko kontestu hori gogoan izatea, Instrukzionea gazteriarentzat delako liburuxka duela berrehun bat urte nola agertu zen konprenitzeko. Ez baita hutsetik sortu den zerbait.

Iraultza denboran desegin ziren elizaren egiturekin zer-ikusi handia izan zuten ororen eskolak, eta toki anitzetan, herri eta hiri tikietan bereziki, gibelamendu zerbait izan bide zen eskola herrikoien sisteman ${ }^{20}$. Gauzak baretzen hasi zirenean, piskanaka abiatu ziren eskola berriak, eta hain zuzen garai hartan egin zen itxura guzien arabera ere gure liburuxka, Vinsonek bere bibliografian (1891: § 143) aipatu zuena. Hona zer zioen ${ }^{21}$ :

Instructionea gazteriarentçat. Adrien Emperadorearen galdeac sei urthetaco haur bati. Signé : Beaumont. 
Pet. In-8-24 p.

S. t. l. nid. (vers I795)

Argitara-urterik eta lekurik gabe eman gabe egin zen, beraz, 24 orrialdeko liburuxka hori, Iraultzaren garaian, 1795aren inguruan, Vinsonen orduko ustean. Esplikaziorik ematen ez badu ere urtearen finkatzeko, argi da Vinsonek ikusi zuela lan horretan Thermidorreko gertakarien ondoko urteetan egin lan bat.

Handik zenbait urteren buruan, 1898an argitara eman zuen gehigarrian zuzenketa bat egin zuen Vinsonek horretaz, liburuxka menturaz 1801 edo 1802an argitaratu zela aditzera emanez :

Il est dit dans cette brochure que le monde a été créé il y a 6804 ans; c'est évidemment une faute d'impression pour 5804, car il y est dit aussi que J.-C. vécut 4000 ans après la création du monde. La brochure serait donc de 1804. Cette hypothèse est confirmée par un passage où la découverte d'Uranus (1781) est indiquée comme datant déjà de 25 ou 30 ans. Il est vraisemblable que cette plaquette a été écrite entre le Concordat (1801) et l'arrivée à Bayonne de l'évêque J.-J. Loison, le 4 nivose an XI (25 décembre 1802).

Gehigarrian, beraz, 1801edo 1802an finkatu zuen Vinsonek liburuxkaren idazketa, Bonaparte Lehen Kontsulatuak Aita santuarekin Konkordatua egin ondotik, baina Konkordatuaren ondoko lehen apezpikua etorri aurretik.

Ez da dudarik liburuxka Inperioa jarri baino lehenago egin zela, aditzera ematen baita hartan Frantzia errepublika dela [21. o]. Halere Aita santua batere ez baita aipatzen delako liburuan, aditzera ematen baita hartan Frantzian errepublika dela [21] konkordatua egin baino lehenago ere idatzi zela instrukzione hori, $1795-1800$ urteetan, beraz.

Liburuxkak 24 orrialde ditu, eta bi testu dauzka. Lehen zatiari dagokion izenburua Vinsonek ekartzen duena da : Adrien Emperadorearen galdeac sei urthetaco haur bati (1-13 o.); bigarren zatiak, haatik, beste izenburu bat du : Haurren instructionea galde eta ihardesteca, edo haur gazte batec, necessario dituen eçagutcen moldea (13-24 o.). Ez dira idazlan bakarreko bi parte, baina bi testu desberdin, elkarren osagarri ere ez direnak, baitira bigarrenenan lehenbizikoan agertzen diren ikasgaiak, errepikatzen direnak.

Izenburu horiek erakustera ematen duten bezala, liburuxka katiximen moldeari darraio, erran nahi baitu galde-ihardespenez osatua dela burutik buru. Garbiki agertzen da, bestalde, maila behereko irakaskintzari dagozkiola bi testuak, nahiz bigarrena lehena baino eskolarakoago den.

Lehen zatiko galdeak ez dagozkio dotrinari. Hala ere, erlijio historietako zenbait kontu aipu dituzte : munduaren kreatzea, uholdea, bibliako pertsonaia batzuk (Adam eta Eba, Noe, Jose, Abraham, Isaias,...). Oraingo ikusmoldean erran daiteke erlijio kulturaz ari dela parte hau. Erlijio testuetan finkatua izanik, maila berekoak balira bezala ematen dira hartan erlijioari berari datxikion irakaspena eta natura zientziari buruzkoa. Adibide gisa eman daiteke, beste anitzen artean, bi zeruen artean egiten den diferentzia [3. o] :

Zein dire munduaren pharteak? Printzipalak dire, zerua, laur elementak̆, zeinak. baitire sua, airea, lurra eta ura.

Zenbat zeru dire? Bia prinzipalak; anpirea eta firmamenta.

Zer da zeru anpirea? Hura da zeru guzietarik gorena, hedatuena eta ederrena.

Zer da zenu firmamenta deitzen dena? Hura da klaritate dibinoaren argia, dohatsuen egoitza. 
Literatura herrikoietan maiz gertatzen den bezala, irudi hitzez argitzen dira ezjakintasunaren eremuak, hala nola ikus daitekeen galde-ihardeste segida honetan $[3,0]$ :

Zerk dauka lurra? Aireak.

Zerk dauka airea? Laur ebanjelistek.

Zerk dauzka laur ebanjelistak? Su izpiritualak.

18. mendeak zenbakien aldera erakutsi duen isuria aurkitzen da hemen ere bibliako kontuei aplikatua : Noeren adina arkua egiten hasi zenean, zenbat urte eman zuen egiteko, zenbat denbora egon zen urean arka, zer neurri zituen arkuak, etab...

Liburuxkaren bigarren galdekizuna, gaiaren aldetik, ez da. lehenbizikoa bezalakoa. Lehenik, erlijio gai batzuk aurkeztuz ere hastean, hartaz kanpoko kontu batzuez ari da, mitologiako eta historia eta geografiako gaiak aipatzen dituelarik gehienik : zerua zer den, planetak zenbat eta zein diren, denboraren partikamena, kontinenteak, munduko obra handiak (Babilionako murruak, Rodosko estatutua, Alexandriako dorrea, Egiptoko piramideak, etab... Minosen labirintoarekin batean), Termopiletako bataila, errepublika eta monarkiaren definizioak, itsas gora-beherak, lurraren mugimendua eguzkiari buruz, ibaiak nola sortzen diren... Testua errepublikazalea da, baina errepublikazaletasun hori antzinateko eta bereziki Espartako kontuak aurkeztean agertzen da, iraultza garaiko nahasmenduak aipatzen ez direlarik [21-22] ; erregeen kontrako solasik ez da, batere.

Testuaren adierazpenak guztiz argiak dira eta egoki emanak. Adibidez, hona nola esplikatzen den euriaren moldatzea [17-18] :

Nahi nuke Jakin nondik heldu den uria? Iisaso, arribera eta bertze lurraren gainean diren ur guzietarik.

Trufatzen zira: nola igan daiteke zemira itsasoan eta arriberetan den ura? Erranen derautzut : uria formatzen da batzuetan arriberen gainean, ikhusten ditutzum lanhoez, erran baititeke khea dela. Bada, khea iduritzen zautzun gauza hura, da uraren pharterik mehena, zeina deitzen baita baphorea, eta zeina baita hainitz sarkarria; bada, iguzkiaren berotasunak, tiratzen tu bethi uraren pharterik finenak, alxatzen dira airean, baphoretan, eta aireak atxikitzen $t u$, hainitz ez denean; bainan noizetare baita kantitate handi bat, aireak ez ditzake gehiago jasan, urak lehertzen du airea, eta erortzen da uritan lurraren gainerat.

Itzulpen edo menturaz moldaketa lana da, zeren bi parteetan ez baita beti segida handirik aurkitzen aipatzen diren gaien artean.

Mintzaira aski ona da, galde-erantzunen bizitasuna eskaintzen duena eta haurrek gogoz ikasteko egokia.

\title{
6. Testuaren argitalpen berria.
}

\author{
INSTRUCTIONEA, GAZTERIARENTÇAT:": \\ ADRIEN EMPERADOREAREN GALDEAC \\ SEI URTHETACO HAUR BATI
}

Sei urthe baicic etçuen haur hura; deithua cen mundu guciaz, Emperadorearen ilobassoa; handizki, errecomendatua cen Jerusalemgo patriarka 
bati. Haur hura erromarat ethorri cenean, interrogatua içan cen, dukez eta chivalierez. Estonatu cituen guciac. Adrienec, ceina orduan Erroman baitcen, erakhar araci çuen interrogatua içaitecotçat, bakotchaz irakurriac içaitea, mereci duten hainitz questioneren gainean.

\section{Adrien Emperadorea.}

G. Nola eguina içan da cerua?

[2] I. Eguina içan balitz guiçonen escuz, jadanic eroria içanen cen, eta sorthua içan balitz, aspaldion hila içanen cen.

G. Cer eguin çuen Jaincoac lehenic ?

I. Arguia eta clartassuna dembora gucietan.

G. Nola adi daiteke trinitate Saindua dela Jainco bakhar bat, hirur presunetan erreguinatcen duena?

I. Iguzkitic, ceintan aurkhituco baitituc hirur gauça; hala-nola, içaitea, arguia, eta berotassuna ceinac ecin separatuac baitira, ecic bat ez-ciatekec içan bertcea gabe.

G. Jaincoa, dembora lucez egon cen munduaren creatcen ?

I. Beguia idec artea becembat, ecic mundua creatu çuen instant batez; bainan sei egunic barnean, eguin cituen, diren gauça guçiac : hala-nola, igandean creatu cituen, aingueruac eta archanyeluac; astelehenean eguin çuen firmamenta, erran nahi da, iguzkia ilharguia (:ilkarguira) eta içarrac; astehartean eguin cituen lurra eta itsassoa, aincirac, ur eztiac, chirripa eta ithurriac ; asteazkenean eguin cituen chori eta arrain suerte guciac; ortcegunean eguin cituen planetac, ortcilarean eguin eta formatu cuen Adam, bere idurira ; larumbatean, errepausatu cen eta benedicatu cituen eguin eta formatu guciac.

[3] G. Certaz Jaincoac composatu du lurra?

1. Materia diferentez eta urez; eta lur hunec baitu bederatci mila lekoaren inguruna, itçulian, eta hirur mila loditassunean.

G. Jaincoa larumbatean errepausatu cenaz gueroz certaco guelditcen guira gu, lanetic, igandean, larumbatean lanean hari içan ondoan?

I. Juduekin bestan betan ez aurkhitcea gatic ; eta ceren igandean phiztu baitcen J. Christo ; bascotic, çazpigarren [testuan : caz pigarren] igandean, mendecoste egunean, egorri baitcioen, izpiritu [testuan : izpititu] saindua bere Eliçari.

G. Cein dire munduaren pharteac ?

I. Printcipalac dire, cerua, laur elementac, ceinac baitire sua, airea, lurra eta ura.

G. Cembat ceru dire?

I. Bia principalac; ampirea eta firmamenta.

G. Cerda ceru ampirea ?

I. Hura da ceru gucietaric gorena, hedatuena eta ederrena.

G. Cerda ceru firmamenta deitcen dena? 
I. Hura da claritate dibinoaren arguia, eta dohatsuen egoitça.

G. Cerc dauka lurra ;

I. Aireac.

G. Cerc dauka airea [testuan: aireac] ?

I. Laur evanyelistec.

[4] G. Cerc dauzca [testuan: dauzea] laur evanyelistac?

I. Su izpiritualac.

G. Cein da behinere uriric eguiten ez duen, eta behinere eguinen ez duen lrkhua?

1. Gelboeco sorhoa, Egipto gucian, ceren lurra trempatua baita, nilaz.

G. Cembat mihi dire munduan?

I. Badire hirur hogoi eta hamabi.

G. Norc eman cioten icena, animale guciei ?

I. Adamec.

G. Cein da munduan den gauçaric mendrena?

I. Guiçonàten gorputça, arima campoan denean.

G. Cein da munduan den grauçatic atinena eta segretena?

I. Guiçonaren pentsamendua.

G. Mundu honetan bere guthicia eta borondatearen cguiten dutenac, urus dire?

I. Ez, ez dire urus; baina urus dire, Jaincoac, mundu huntan, bere borondatearen [testuan : bererberondatearen] eguitera urzten ez dituenac, eta nahigabez gaztigatcen dituenac.

G. Cein da aberatsentçat [testuan : aberatsentcat] beçala, pobreentçat den gauçaric cruelena?

I. Herivil, ceintan, Jaincoari condu emaitera, Johan behar baita, gure bici onaz edo gaichtoaz.

G. Cein da, guiçona asse ez daitekeyen gauça?

I. Irabacia ! ecic guiçona, ceruco gloriaren irabaztera entseyatu behar bidean, ez da entseyatcen [5] aberatstassunen irabaztera baicic.

G. Cein da gauça hoberena [testuan : boberena] edo gaichtoena?

I. Solassa.

G. Norc eguin çuen lehenbicico Eliça?

I. Jondoni Pauloc.

G. Cer adin çuen Noëc bere arkharen eguiten hassi cenean ? 
I. Bacituen bortz ehun urthe.

G. Cembat urthe eman çuen arkaren eguiten ?

1. Ehun urthe.

G. Cembat egun egon cen arkha hura urean ?

1. Berrogoy [testuan: Berroigoy] egun.

G. Arkha harc cembat çuen, lucean, largoan eta goran ?

I. Bacituen hirur ehun besso lucean, berrehun eta laur hogoy, goran, eta berrogoy eta hamar, largoan.

G. Cein lekhutan da orai arkha hura?

I. Armenian, mendi gora baten gainean, ceina deitua baita Archeteclin.

G. Norc landatu çuen lehenbicico mahastia?

I. Noëc. na?

G. Norc galdeguin çuen, egundaino nihorc galdeguin duen, dohainic handie-

I. Joseph Arimathiacoac, ceinac galdeguin baitçuen J. Ch. gure jaunaren gorphutça, gurutcean celaric, eta eçarri [testuan : eçarric] baitçuen thomban.

[6] G. Certaco behar da barurtu, ortcilarean, bertce egunetan baino lehenago, eta ez da haraguiric jaten?

I. Çortci arraçoin printcipal gatic : lehena [testuan : lchena] ceren Jaincoac, egun hartan eguin baitçuen Adam : bigarrena ; ceren ortcilarean, bathayatu baitçuen Jondoni Juanic, J. Ch. gure jauna Jourdaingo arriberan, hirurgarrena, ceren ortcilarean, hil baitçuen, davitec goliat digantea : ceren ortcilarean hartu baitçuen J. Christoc, haraguizco gorphutza, ama biryinaren sabelean; bortzgarrena, ceren egun hartan berean bathayatua içan baitcen, Jondoni Eztebe, lehen martira : seigarrena, ceren ortcilarean, ebaki baitcioten burua, Jondoni Juani Baptistari : zazpigarrena [testuan : gazpigarrena], ceren ortcilarean gurutceficatua içan baitcen J. Christo ; çortcigarrena, ceren ortcilarean, ethorrico baita goure jauna, Josaphateco sorhora, mundu guciaren juyatcera.

G. Cein dire Jaincoari, agradagarrien caizcon gauçac ?

I. Eguiazco penitencia, pacientcia, pobrecian, eta bekhatutic beiratcea.

G. Cembat seme-alaba içan cituen Adamec ?

I. Hamar seme eta laur hogoy alaba, khondatu gabe Caïn, Abel eta Seth.

G. Cein cen lehenbicico ohoina?

[7] I. Seth.

G. Nor sartu cen lehenic parabissuan?

I. Ohoin ona.

G. Nor cen bi aldiz hil cena? 
I. Lazaro, behin pitztu çuen ]. Christoc.

G. Norc eguin içan du lehenbicico hiria ?

I. Cain, Adamen lehen semeac.

G. Cembat galtzapen suertetan eror daiteke guiçona?

1. Hirur suertetan : lehena, bere ontassunen galtçapenaz, bigarrena, bere ossassunaren galçapenaz, hirurgarrena, bere arimaren [testuan : arimeren] galtçapenaz.

G. Nondic heldu da çuhurtcia ?

I. Jaincoaren beldurretic; ecic çuhurra dena, bera gaztigatcen da.

G. Certara Jaincoac obligatu ditu guiçon guciac ?

1. Lanera, Jondoni Pauloc dio, hain [testuan : nain] errech dela guiçonarentçat lanean hartçea, nola choriarentçat [testuan : chorierantçat] hegaldatcea.

G. Certaric eguin içan ditu Jaincoac, guiçona eta emaztea ?

I. Guiçona eguin içan da lurretic ; eta emaztea eguina içan cen guiçonaren saihets heçurretic, ceina athera baitcioen Jaincoac lo çagoelaric.

G. Cembat bici içan dira Adam eta tuva?

I. Bederatci ehun urthe.

G. Cein da, Jaincoaren aitcinean, gutien [8] barkhatgarri den bekhatua?

1. Desesperacionea.

(i. Cein da guiçonec lurraren gainean duten eguitecoric premiazcoena?

I. Hura da, Jaincoaren eta J. Christoren eçagutcea eta bere buruen eçagutcea ; erran nahi da, cer diren eçagutcea, certaco bici diren, cer bilhacatu [testuan : bilhaçatul behar diren bicitce hunen ondoan, eta cer eguin behar duten eguiazki urus içaiteco ; hitz batez, Jakin erreliyionea, eta bici haren arabera.

G. Cein da Jaincoac, guiçonei eguin derayen lehen misericordia?

I. Heyer, salbatçaile baten hitz emaitual, ceina igurikia içan baita lurrean, bederen laur mila urtheren inguruna.

G. Dembora lucea du, Jaincoac, cerua eta lurra creatu cituela ?

1. Badu 6793, urtheren inguruna.

G. Cein da Juduen lehen erreguea?

I. Saül.

G. Cein cen, iguzkiaren gueldi-arazteco dohaina içan çuena?

I. Josuë, Gabaonitarres seguitua cenean.

G. Nola deitcenda, Abrahamec bere seme Isaac, sacrificatu nahi içan çuen mendia? 
I. Moria, Calvarioco mendiaren aldean, ceintan J. Christo gurutceficatua içan baitcen, han-[9]dic cenbait menderen buruan.

G. Segur guira badela Jainco bat ?

I. Bai : eguia bat [testuan: qat] da hain clara, nun burua galdua behar baita, ukhatceco edo dudatceco ; ecic ez da burua galdua duenic baicic, Jaincoric ez dela divenic (ps. 13. vol. V.).

G. Cein dira J. Christoren Sortcea, aincinetic erran duten prophetac?

I. Jacob, Daniel eta agea. nac?

G. Cein dira, messiaz baino lehenago aguertu diren berrce propheta famatue-

I. Elia eta Isaïas.

G. Cer eguindu Eliac erremarkablenic ?

I. Laur urthez gueldi araçi içan ditu ceruco uriac; hil araci laur ehun eta berrogoi eta hamar aphez faltsu. Hacia içan da bele batez, guero aingeru batez, eta altchatua cerurat, urrezco carrossa batez.

G. Cer eguin du Isaïac erremarkablenic ?

I. Harc, erran içan du clarkienic, J. Christoren sortcea, bicitcea [testuan : bicetceal eta heriotcea.

G. Cein familietaric atheratu dire Juduac ?

I. Isaac eta Jacob, Abrahamen seme eta ilobassoetaric.

G. Cembat urthe çuen munduac, hassia cela, J. Christo Maria Birginaren ganic sorthu cenean?

I. Laur mila urtheren inguruna.

[10] G. Cein içan cen Jaincoaren contra eguina içan cen lehen bekhatua?

I. Urguilua.

Cein içan cen avariciosic handiena eta icigarriena?

I. Judas traidorea, ceren saldu baitçuen bere naussi dibinoa hogoi eta hamar diru pecetan [testuan : ppecetan], ceinec eguiten baitutu gure monedaco hamar luissen heina. cea?

G. Cein egunez, hitzeman cioten traidore harc Juduei, bere messiassen largat-

I. Asteazken [testuan : Azteazten] saindu goicean.

G. Cein da egundaino içan ez çuena, eman duena?

I. Jondoni Juani, noizetare bathayatu baitçuen gure Jauna, Jourdaingo heguian.

G. Cein da lekhua, iguzkiac arguitu duena, eta berriz behinere arguituco ezduena? 
I. Hura da Moïse, oinac idorric, passatu cen itsas gorrico lekhua, eta Pharaon, bere armada guciarekin itho cena.

G. Mundua hassiz guero, ez da içan egun bat ceintan ez baitçuen eguiten ez egun ez gau?

I. Bai : hura cen J. Christo gurutceficatu cen eguna ; ecic hirur orenez içan cen Eclipsac, eguin çuen, ez egun içaitea, ilhunbeac hedatuac cirenaz [testuan : ecirenaz] gueroz lur gucian. Etcen gau ere, [11] iguzkia, urrun etçana içaitetic, bere curtsaren erditan cenaz gueroz; eguerditic hirur orenetaco heinean, eguna aguertu cen.

G. Cein içan ciren, J. Christoc gurutceco arbolaren gainean, erran cituen lehen hitçac?

I. Hauc ciren : in manus tuas, Domine, comendo Spiritum meum.

G. Cein içan cen, egundaino nihorc jassan içan duen Guerlaric handiena eta odoltsuena?

I. Juduen Guerla, Erromanoen contra, J. Christo hil cenetic, hogoy eta hemeçortci urtheren buruan.

G. Cer içan cen guerla haren ondorioa?

I. Josephen historioac, dakharke, gosetea hain handia içan cela, nun içan baitciren, Jerusalemen bere haurrac Jan cituzten amac.

G. Cembat içan cen hil eta presuneren nombrea?

I. Hilac içan ciren berrehun eta hogoi eta hamaçazpi mila baino guehiago, eta laur ehun eta hamaçazpi mila pressuner [testuan: pressunez].

G. Norc ereman çuen bictoria?

I. Erromanoec; eta gueroztic Juduac barrayatuac dire lur gucian, erregueric batere gabe.

G. Cembat denboraz içan da persecutatua Eliça Catholicoa?

Hirur ehun urtheren ingurunaz, pagano Em-[12]perador diferentez.

G. Cein içan cen lehenbicico persecutatu işin çuena?

I. Neron, J. Christo hil cenetic hogoi eta hamar urtheren buruan.

G. Badakiçu persecutatçaileric ikharagarrienen nombrea?

I. Bai. Çortci dira eta guciac, miserableki hil dira.

G. Cein içan çiren persecutioneric lucenac eta cruelenac ?

I. Diocletien eta Maximienenac; ecic iraun çuten berrogoi eta hamar urthez, guelditu gabe.

G. Cein içan cen persecucione hec akhabaraci eta Eliçari bakhea [testuan : bakinea] içan araci cioena?

I. Constantin Emperadorea Santa Helenaren semea, ceina bathayatua içan baitcen $312 \mathrm{an}$. 
G. Cembat bathayo suerte dira?

I. Hirur ; urezcoa, odolezcoa eta Guthiciazcoa.

G. Cein içan cen lehenbicico heresia ?

I. Lehenbicicoa, Apostoluen beren demboran, pitztua içan cen Simon magicienaz ; malurus hura Jaincotçat nahi cen passatu, cioelaric dirutan eros şaitekela, Ispiritu Sainduaren emaiteco botherea; bainan lurrerat egotcia içan cen Jondoni Petriz erroman.

[13] G. Nor dira munduaren akhabantçan baicic hilen ez direnac ?

Enoeh eta Elia, ceinac, eramanac içan baitira biciric, lurreco parabissurat, eta ethorrico baitira munduaren akhabantçan antechristen attakatcera.

HAURREN INSTRUCTIONEA

GALDE ETA IHARDESTECA (testuan : IHARDESTEGA), EDO

HAUR GAZTE BATEC, NECESSARIO DITUEN EÇAGUTCEN MOLDEA

G. Norc eguin ditu, cerua, lurra eta içaitea duten gauça guciac ?

I. Içaite eternal harc, ceina, bethi danic içan baita, eta bethi içanen baita, eta ceina deitcen baitugu Jaincoa.

G. Adoratu behar dugu, eta eskherrac bihurtu behar diotçagu, hoin bertce miracuiluren eguile guisa?

I. Bai, guiçon guciec çor diote eçagutçazco tributu bat, instant guciez eguiten deraizcun ongui eguinen aldera.

[14] Nola deitcen dute Jaincoaren adoratceco manera?

I. Erreligionezco adoracionea.

G. Cer da guiçona ?

I. Hura da creatura arraçoinable bat, gorputz eta arima batez composatua.

G. Cer deitcen duçu gorphutz bat ?

I. Hunki detçakeguken gauça guciac, gorphutza formatua da, laur principioz, ceinac deithuac baitire elementuac.

G. Cembat centsu tuzte, guiçonac eta animalec ?

I. Baituzte bortz ceinac baitire, bista, ussaina, aditcea, gostua eta unkitcea.

G. Cer da cerua ? dena.

I. Hura da munduaren pharteric gorena, eta bertce hainitz phartetan çatitcen

G. Cer da firmamenta?

I. Hura da guc ikhusten dugun ceruaren phartea, ceinetan baitire arguiac.

G. Cer deitcen duçu arguiac ? 
I. Içarra (sic) eta planetac.

G. Cembat içar dire?

I. Ez daitezke konda.

G. Cembat planeta dire?

I. Çazpi : cein baitira, iguzkia, ilharguia, mars, mercura, jupiter, venus eta saturna; bada bertce çortci garren bat, herschell deithua, orai duela hogoi eta bortz edo hamar urthe deskubritu due-[15]naren icenetic.

G. Cein da planetetan den handiena?

I. Iguskia.

G. Certaco cerbitçatcen da iguzkia ?

I. Lurraren arguitceco, belhar eta animalen sorharazteco, heyen bici eta handi arrazteco (sic) munduaren hastetic, iguzkiac arguitcen tu guiçonac, eta preciski behar den beçala eçarria da, guretçat abantailos içaiteco ; gorago balitz, lurra ecin bero leçake ; beherago balitz, erre leçake, bai gu ere.

G. Certaco cerbitçatcen da oraino iguzkia?

1. Orenez, egunez, artez, hilabethez, sassoinez, urthez eta mendez, guiçonen biciaren erreglatceco

G. Cer da orena?

I. Hura da demboraren iraupen bat, ceina partitcen baita bietara oren erdiaren eguiteco, edo lauretara, oren laurdenaren eguiteco edo hirurhogoi pharteta$\mathrm{ra}$, ceinac deitcen baitira minutac.

G. Cembat oren tu egunac?

1. Hogoi eta laur, juntatuz gabazcoac.

G. Cembat egun dire urthean?

1. Hirur ehun eta hirur hogoi eta bortz.

G. Cembat hilabethe dire?

I. Hamabi.

G. Eta aste urthean ?

I. Berrogoi eta hamabi.

G. Cer da mendea?

I. Hura da ehun urthetaco dembora.

G. Cembat sassoin dire urthean?

[16] 1. Laur : hala-nola, primadera, uda, udaskena, eta negua.

G. Norc landatu çuen [testuan: laudatu] lehenbicico [testuan: leheubicico] mahastia?

I. Noëc.

G. Noëc içan çuen haurric ? 
I. Içan çuen hainitz; bainan lehen bicico liburua ezda mintço hirurez baicic, ceinac baitira printçipalki, Sem, Cham eta Japhet.

G. Erran diçadaçu, Noëren cein haur içan cen gure aita?

I. Japhet.

G. Noëren haurrac bethi elkharrekin egonciren?

I. Ez, bereci ciren, Babelen dorrea, ecin akhabatu çutenean; eta bacotchac bere aldetic pentsatu çuen Joatea, chan $\mathrm{n}$ umeac, Joan ciren orienteco alderat Japhatenac, occidentecotat, et Semenac guelditu ciren, assar deitcen cen lekhuan.

G. Erran diçadaçu cein aldetan dira Europa, eta munduaren bertce pharteac ?

I. Europa, nortean da, Afrika eguerdian, Asia, orientean, eta Amerika occidicntean.

G. Aditu dut badela lekhu bat, ceintan iguzkia gure ganic hurbilago baita, eta ceintan eguiten baitu berobat ecin Jassanezcoa?

I. African eta Asiaren eguerdico phartean da, bainan bero hura ez da ecin Jassanezcoa ; direnaz [17] gueroz lekhu hartan yendeac, hura yassaiten dutenac: hala African eta Amerikan sortcen direnac, bero eguiten duen lekhuetan, ongui ekhartcen dire, bainan campotarrac eritcen dire.

G. Aditu dut oraino badela lekhu bat, behinere uriric eguiten ez duena, edo arraroki?

I. Bai, Egiptoan da : hargatic hainitz bero eguiten du. Jaincoac ceinac ez baitçuen nahi uritic eguin ceçan, eman içan du arribera handi bat, nil deitcen dena ; urthe guciez atheratcen da bere ohetic, eta estaltcen tu Egiptoco lur guciac hainitz hilabethez; eta miragarri dena nilgo urec, berekin eremaiten dute [testuan: duten] lurren gainera, ichtil bat, ceinac eçartcen baititu, gauça eccelenten ekhartceco [testuan: echartceco] heinetan.

G. Nahi nuke Jakin nondic heldu den uria?

I. Itsasso, arribera eta bertce lurraren gainean diren ur gucietaric.

G. Trufatcen cira : nola igan daiteke cerura itsassoan eta arriberetan den ura?

$<[\mathrm{I}]>$ Erranen derautçut : uria formatcen da batçuetan arriberen gainean, ikhusten ditutçun lanhoez, erran baititeke khea dela. Bada, khea iduritcen çautçun gauça hura, da uraren pharteric mehena, ceina deitcen baita Baphorea, eta ceina baita hainitz sarkarria ; bada, iguzkiaren [testuan : iguzkiarren] berotassunac, tiratcen tu bethi uraren pharteric finenac, [18] alchatcen dira airean, baphoretan, eta aireac atchikitcen tu, hainitz ez denean; bainan noizetare baita quantitate handi bat, aireac ez ditçake guehiago Jassan, urac lehertcen du airea, eta erortcen da uritan lurraren gainerat.

G. Erran diçadaçu, orai cembat miracuilu diren munduan?

$<[I]>E z$ daitezke konda : ecic inguratcen gaituzten gauça guciac miracuilu dire, eta Jainco baten içaitea erakhusten deraukute; bainan badire çazpi guiçonen escuz eguinac. 


\section{G. Erran detçagutçu?}

1. Asian, Babiloniaco murruac eta Baratceac, Egiptoan, Alexandriaco dorrea, Mausoleren thomba, Rhodesco colossa, Ephesan, Dianaren templua, Cretaco irlan Minossen labyrintha, eta Egiptoco piramideac.

G. Erran deçaguçu, cer ciren Babiloniaco murruac eta barratceac, miracuiluetaric bat?

I. Babiloniaco murruec inguratcen cuten hiri hura, munduco Emperadoretassunic çaharrenaren capitala; inurru harc [testuan: narc] baçuen luçean, berrogoi eta hamar milla, eta berrehun pia goran : eta largoa cen, nun sei carrossa passa baitcitazkeyen, bat-bertcea deinatu gabe. Babiloniaco baratceac içan dire obrabat, haren murruac beçain miragarria. çuen?

[19] Explica dieçaguçu cer cen Alexandriaco dorrea eta norc eguin araci

I. Içan cen erregue bat, Ptolomeë deitcen cena, ceinac eguin araci baiçuen marbolezco dorre bat, hain ederra, nun çazpi miracuiluetaric bat deitu baitçuten : eçartcen çuten, dorre haren gainean argui bat, Pharos deitu çutena, untcien abertitceco ; eta gueroztic, Pharos deithu tuzte, gavaz itsassoan direnentçat, arguia eçartcen tuzten lekhu altchatuac.

G. Explica diçadaçu cer cen Mauseleren thomba?

I. Bacen Caria, Asia ttipieneco erresuma tipi batetaco, erreguina bat, arthemisa deitcen cena, bere Senhar Mausolea hainits maite çuena. Mausolea hil cen, eta erreguinac cguin araci cioen thomba eder bat : eta gueroztic, Mausoleac deithu thuzte hilen orhoitçapenaren [testuan : orthoitçapenaren] ohoratceco cguiten diren obrac. Bainan [testzan: Bainean], nahiz arthemisac eguin araci çuen thomba, ederra cen, etçuen asqui aurkhitu bere senharraren hautsen errecibitceco: nahastekatcen cituen egun guciez, bere çopa eta arnomrekin : eta hola arras iretsi cituen.

G. Erraguçu cer cen Rhodesco colossa?

I. Rhodesco colossa cen metalezco potret bat, guiçon, handitassun icigarri batetaco, baten figura çuena. Rhodesco [testuan: Bhodesco] hirico portuaren sartcean [20] cen, icen hortaco irlan; hain gora cen, eta haren [testuan: karen] çangoac, harroca, elkhar ganic hain urrun cirenen gainean phausatuac, nun untciac bela bethean, passatcen baitciren, çangoen artetic : aurtikhia içan cen lur ikhara batez.

G. Erradaçu cerc eguinarazten duen lur ikhara?

I. Lurpeco su handi batçuc, edo lurrean cerratuac diren haice batçuc, ceinec enfort eguiten baitute atheratceco, eta batcuetan, bide bat idekitcen baitute, atheratcen baitira eta hedatcen.

G. Aditu dut badirela lekhu batçu, eta particularki, Europan, cicintan aurl hitu baitira, su egotzten duten mendi handi tut u : nola deitcen tuzte hec?

I. Deitcen tuzte volcanac.

G. Nola deitcen tuzte volcan hec diren lekhuac? 
I. Bada bat Italian, Naples deitcen den hiri baten aldean ; vesuva, deitcen den mendi handi baten gainean da : bada bertce bat Sicilaco irlan etna deitcen den mendi baten gainean; eta bertce bat, Irlandaco irlan [testuan : irlant], heclaco mendiaren gainean.

G. Bihur gaiten çazpi miracuiluetarat ; cer cen Dianaren temploa ?

I. Dianaren temploa cen, Ephesaco hirian asiaco heguietan, Diana Jaincossari consecratua içan cen, Edificio eder hura; Herostrate astrugaitçac, istorioan famos errendatcea gatic, erre çuen.

[21] G. Erradaçu cer cen Minossen labyrintha?

I. Hura cen etche bat, halaco guisaz eguina nun han sarthuz gueroz, ez baitçaitakeyen guehiago athera, ez bere bidea aurki ; ecic bacen, mila itçul, inguru : Dedalec eguin çuen labyrintha hura, eta cen Cretaco irlan.

G. Erraguçu cer ciren Egiptoco Pyramideac ?

I. Egiptoco pyramideac ciren obra famatu batçu, laur mila urthe baino guehiago duela eguinac, ceinac agueri [testuan : agueric] baitira oraino, Caira handiaren aldean; Egiptoco Erregueen ehortz lekhutçat cerbitçatcen ciren, hogoi urthe eman çuten handienaren eguiten; eta emplegatu cituzten hirur ehun eta hirur hogoi eta sei mila languile, diote ez cela deus gosta, languilen Janhariaren despendioentçat baicic, ceinac igan baitciren hemeçortci ehun talentutara, ceinec eguiten baitute laur ehun mila libera sterlinken inguruna.

G. Erradaçu orai hea, Francia bethi errepublica içan cenetz ?

I. Ez, Erregueës gobernatua içan cen.

G. Cer da Errepublika bat ?

I. Errepublika bat da, estatu bat, hainitz presunaz gobernatua; ecic, estatu batetan, ez denean presuna choil bat baicic gobernatcen duenic, estatu hura deitcen dute, monarchia.

G. Franciac, cembat erregue içan çituen ?

[22] I. Hirur hogoi eta bortz, monarchia [testuan : manarchia] establituz gueroz.

G. Cein içan cen Francessen lehen erreguea?

I. Pharamond.

G. Erradaçu errepublika çaharren nombrea eta non ciren ?

I. Içan ciren laur : Athena, Sparta, deithua orobat Lacedemonia; hauc biac Grecian ciren : Erroma Italian; eta Carthage African.

G. Cein içan ciren errepublika horietaco legue-emaileac ?

I. Solon Athenaco, Licurga Spartaco eta Brutus Erromaco.

G. Ez ciren hirur ehun Sparciatar chahutu hain glorioski Thermopiletaco passayan?

I. Bai, Leonidassen guidaren azpian, Xercés Persaco erregueren armada handien contra. Erraten diote armada hain handia cela, nun iguzkia itçalia içanen 
baitcen, heyen fletchen ussutassunaz : hanbathobe, ihardetsi çuen Leonidassec ; itçalean batailatuco guira. Thermopiletara cirenean, Sparciatarrac guducatcen dira, lehoinac beçala, hamar aldiz handiago cen armada baten contra; nombreaz lehertuac, chahutcen dira, bat choilki escapatu gabe : bainan curayezco exemplu horrec, salbatu çuen Grecia, hormaraciric ikharaz Xercés, Beroaraciric errepublicanoen Cu-[23]rayea, eta hauyer elkhargana biltceco dembora emanic.

G. Erradaçu cer den passaya bat ?

1. Passaya bat da itsasso batetic bertce bateraco bidea.

G. Erradaçu cer diferentcia den, itsasso arribera eta ainciren artean :

I. Itsasso bat da ur kantitate handi bat bere ohetic atheratcen ez dena, eta kurritcen ez duena atriberec beçala.

G. Aditu dut bizkitartean, itsassoa, bere ohetic edo lekhutic atheratcen cela, explica daçu hori?

I. Itsassoa, egunean bietan atheratcen da bere ohetic, eta han sartcen da: harrec ez du behinere faltatcen. Badakite ere justuki cer orenez : eta hori deitcen da itsassoaren gora behera.

G. Norc atherarazten du itsassoa bere ohetic?

1. Ilharguiac, ceinac tinkatcen baitu airea : aire harc tinkatcen du bere aldian itsassoa, eta atherarazten du alde gucietaric.

G. Bainan, ilharguiac nola tinka deçake, ez da argui handi bat baicic ?

I. Trompatcen cira; ilharguia, gurea beçala lur bat da, iguzkiaren arrayoac, errecibitcen ditu; eta harc iduriarazten dautçu argui handi bat beçala. Bainan erranen dautçut, gugaren [sic: guhauren ?] lurra, [24] airean dela, eta bethi itçultcen dela: hotra cerc emaiten daizcun eguna eta gava. Lurrac, hogoi eta laur oren emaiten du itçultcen; noizetare erakhartcen baikitu, iguzkiari bis-à-bis, eguna dugu eta noizetare erakhartcen baikitu bertce alderat, gava, dugu.

G. Uste nuen iguzkia itsassoan etçaten cela?

I. Iguzkiac behi arguitcen du : etçaten da guretçat ; erran-nahi-da, ikhustetic guelditcen guirela : Bainan dembora berean, Jaikitcen da Amerikako populuentçat ; erran nahi da, bere aldian haren ikhusten hasten direla : Bada, çaharrec etçuten America eçagutcen, etçakiten lurra biribila dela, eta inguruna gucian habitatua dela.

G. Erradaçu nondic atheratcen diren arriberac?

I. Ordinariozki mendietaric atheratcen dira arribera badoha bethi, bertce arribera bat aurki arte ceintan galtcen baita : bainan, ez badu, bere bidean, aurkhitcen, arriberaric eta Joaten bada itsassoraino, orduan deitcen dute fluvioa. Fluvioa da arribera handi bat, ceinac eremaiten baitu ordinariozki, bere içena itsassoraino. Aincira da itsasso ttipi bat beçala, ecic hango urac ez du kurritcen. 
1. Sérurier-ek (1874) eta Soulicek (1880) diotenaz, eskolak edo errejentak 1385 an jadanik aipatuak dira Biarnon: Oloroen, Nabarrenkoxen, Lacq-en, Coarraze-n. Halaber, errejent bat bazen 1464 an herri hauetan : Feas-en, Gan-en, Laruns-en, Pauen.

2. Baionan 1498an Johan de Langueirori diruz sariztatu zitzaion la pene et tribailh que a agut en l'an passat per endoctrinar los enfans de la dite ciutat; ik. Soulice (1880:02). 16. mendearen bigarren partean baziren gisa horretako eskola herrikoiak, kartierka antolatuak, eta, protestantismoa zela-eta, hirirarrek bazuten haurrak haietara igortzeko obligazioa; ik. Soulice (1880), Hourmat 1986 (227-228). Baionako kolegioa, maila goragoko eskolatzea eskaintzen zuena, 1598 an ireki zen.

3. 1698an Erregearen adierazpen batek errejenten egoera segurtatu nahi izan zuen, herriei gutieneko hilabetesaria (150 liberakoa mutiko eskoletako errejententzat, 100 liberakoa neska eskoletakoentzat) emateko obligazioa sortuz. Halere herrietan beretan gauzak ez ziren orotan berdin joan; ik. Butel \& Mandon $(1977: 25-26)$.

4. Ez dakigu euskal herrialdeetan Biarnon bezalako mugimendurik izan ote zen I6. mendea baino lehenago. Belapeyrek ematen dituen lehenbiziko erreferentzia juridikoak 17. mendearen hastapenekoak dira : rien ne peut contribuer d'avantage à la conservation de la pureté de nôtre religion, et à la réformation des mours, que l'établissement des petites écoles sous la sage conduite des bons régens; c'est pourquoi l'Assemblée genérale de Melun a ordonné au titre 38 de Ludi Magistris, conformémént au Concile de Latran, qu'il y sera pourveu incessamment, et par l'édit de 1606, art. I4. les mâtres d'école des villes ou villages doivent être approuvés par les curés des paroisses, enfin qu'il a été prescrit que les supérieurs ecclésiastiques pourvoiront aux plaintes desdits régens.

5. Baionakoari dagokionez zeiharkako informazioa baizik ez dut atxeman literaturan, baina katiximen argitalpenak berak aski klarki mintzo dira. Halaber, Zuberoa barnean zeukan Oloroeko diosesari doakionaz, Belapeyreren lekukotasuna dugu, bai eta bestalde 18. mendeko hango apezpikuek izan zuten jarrera ezin argiagoa ere; ik. Castagnet 1997. Akizeko diosesa (Baxenabarren Oztibarre eta Amikuzeko eskualdeak zeuzkana) gelditzen da dudazkoa. Ez da hango euskarazko dotrina berezirik, eta ez dakigu beraz zein katixima erabiltzen zuten. Halere, badakigu 18. mendearen erdian hango apezpikuak oraino galdegiten ziela apaizei tokiko mintzaira erabiltzeko irakaskintzan. Auzi bat izan baitzen horretaz Capbretongo herri gizonekin (Baionan bezala katixima frantsesez egin zedin nahi baitzuten), gogor egin zien apezpikuak, erranez: Les instructions, les cathéchismes (sic) que font les pasteurs et les régents ne se firent jamais pour apprendre une langue, mais pour faire comprendre et retenir la religion, ce qui ne peut et ne doit se faire que dans la langue que les peuples entendent et parlent eux-mêmes. (Sérurier, 1874). Diosesako katixima frantsesez egina zen, baina halere elizagizonei eta errejentei zegokien itzultzea : les curés, vicaires et régents doivent se rendre et l'expliquer en langue vulgaire, sans quoy les peuples ne comprennent rien dans leur religion (idem)

6. Autore horiek erakusten dutenaz, ordainketa aldakorra izan zitekeen, alde batetik irakaskintzaren mailaren arabera, eta bestalde burasoen gizarte mailaren arabera ere. Irakaskintzari dagokionaz, aipatu mailakatze hirukoitzari beste maila batzuk eransten zitzaizkion batzuetan. Horrela, zenbaitetan abezedarioa eta irakurketa bereizten ziren, eta latina ikastea ere karioago izan zitekeen. : En 1670. [...] le régent de Rions reçoit 5 sols par mois des enfants qui sont à l'alphabet, 10 sols de ceux qui lisent, 15 sols de ceux qui lisent et écrivent, 10 sols de ceux qui lisent, écrivent et arithmétiquent. 30 sols de ceux qui apprennent le latin. (Butel \& Manton 1977 : 28).

7. Honela dio Poussouk (1977 : 294) Fleury \& Valmaryren lana aipatuz : En montrant l'étroite corrélation qui existe entre la signature au mariage et l'alphabétisation complète. ils ont levé la principale déftcience qui, aux yeux de beaucoup d'historiens, restait attachée à l'enquête de Maggiolo. Ondorio bera adierazten dute Furet \& Sachs-ek (1974 : 714-737). L. Maggioloren inkestaren ondorioak Statistique de l'enseignement primaire, 2. lib., 1880, argitara eman ziren.

8. Anitzez goragoa zen baionesen alfabetatuen portzentaia, bereziki 18. mendearen hondarrean. 1777 1788 urteetan \% 67,2 da siñatzen dakiten esposlagunen portzentaia baionesen artean. Garai bertsuan Lapurdin zenbaki hauek ditugu:

Uztaritzen 1767-1789 urteetan \% 37,3 gizonetan eta \% 11,97 emazteetan ; Hazparnen 1771 - 1789 urte$\tan \% 29,14$ gizonetan eta \% 9,54 emazteetan; Ezpeletan 1777-1784 urteetan \% 38,2 gizonetan eta \% 4,41 emazteetan. Baxenabarren eta Zuberoan, portzentaiak hobeak dira, hirietan bederen : Donibane Garazin 1777-1785 urteetan \% 46,6 gizonetan eta \% 33,3 emazteetan; Donapaleun 1778-1792 urteetan \% 48,2 gizonetan eta \% 7,1. emazteetan; (ik. Pontet-Fourmigué 1990 : 537). Zuberoan Mauleko datuak ematen 
ditu Poussouk (1977: 308) : 1776-1786 urteetako ezkontagirien arabera, \% 43,8k bazekiten siñatzen gizonetan, eta \% 16,4k emaztetan. Donibane Lohizungo zenbakiak ez ditu ematen Pontet-Fourmiguék, baina beste bi autorek bai, doi bat desberdinak baitira bienak ekartzen ditut hona : Poussouk 1776-1786 urteetako \% 37,8 ematen du gizonentzat eta \% 27,5 emazteentzat. Darrobersek (1994: 82), berriz, 1775-1791 urteetako \% 42,4 gizonentzat \% 38,9 emazteentzat. Ohargarri da Donibaneren kasuan mende hastapeneko portzentaiak berdintsu zirela gizonentzat : 1714-1737 urteetan \% 43,3k izenpetzen dute gizonetan, eta \% 22 , lek emazteetan. Aldaketa handia agertzen da aurreko mendeari konparatuz : $1687-1704$ urteean \% 12,2k siñatzen dute gizonetan, \% 6, lek emazteetan; ik. Darrobers 1994: 81-82.

9. Uztaritzeren kasua adierazgarria da. Hiriko jaunetan esposlagunetan gizon guziek badakite izenpetzen, eta emazteetan lauetarik hiruk, of izialetan hamarretarik seik gizonetan eta hamarretarik batek emazteetan ; laborarietan \% 18k dakite gizonetan eta \% 7k emazteetan ; ik. Pontet ( 1996).

10. Autore zenbaitek diote onespenik gabeko errejentek abezèdarioa eta siñatzen erakusten zutela, eta ez irakurtzen : Les clandestins se contentaient d'apprendre l'alphabet et surtout à signer; leurs clients $n$ 'en demandaient pas davantage, la lecture leur paraissant hors d'atteinte (Darrobers 1994: 81). Pentsa daiteke ageriko eskoletan katixima zenaz gero garrantzizkoena, eta haren irakurketa, bestelako lehentasunak zirela hauetan.

11. Donibane Lohizunen errejenta izendatu zutenean $1676 \mathrm{an}$, herriko buruzagiek galdegin zioten ikasleetan bereizkuntza bat egiteko entre ceux qui ne seront pas aussi avancés dans l'écriture et l'arithmétique que les autres (Nogaret 1925: 106).

12. Pentsa daiteke, menturaz, higenauten ekarria, nolanahi ere 17. mendearen hondarrean arras ahuldua zatekeena, ez zuela kontuan hartzen Belapeyrek.

13. Oraino berantago agertzen da lehen errejentsaren aipamsizi Doninane Lohizuneko paperetan : 1748 an.

14. Kontuan har bedi zerrendak ez direla batere exhaustiboak. 1737ko erreportetan aipatzen diren kasu gehientsuenak agertzen dira horko errejentak onetsiak izan ez zirelako. Batzuetan, halere, erraten da ez dela errejentik parropian ; adibidez, 1737an, Beskoitzen eta Zuraiden. Baina horrelako kasuetan ere, badirudi urte hartako edo orduko egoera adierazten dela, ez egoera iraunkorra.

15. Kanborentzat egiazki erraten da zenbat denbora hartan eskas zutela errejenta. 1747 an, berriz, erraten da badela baina ez dela behar bezalakoa.

16. Haristoyren errana ez da argi. Dio ni confréries ni maitre d'école approuvés, iduri bailuke bazirela baina ez zirela onetsiak.

17. Landesei konparatuz, aitzitik, aurreratuago zen Euskal Herria, Akic cta Mont-ke-Marsan, hango bi hiri handienak, kontuan hartzen ez badira behintzat (ik. Poussou 1977: 309).

18. Halere, Euskal Herrian Biarnon baino tikiago zen sexuen arteko aldea kontu hauetan. Adibidez, ezkonlagunen siñaduretan Mauleko eta Nabarrenkoxeko datuak konparatzen badira 1776-1786 urteetan, ikusten dugu gizonetan Nabarrenkoxtarren portzentaia Mauletarrena baino kasik bi aldiz handiago zela $(\%$ $43,8$ vs $\% 84,5)$, baina emazteetan igualtsu ziren $(\% 16,4$ vs $\% 16,9)$. Biarnon biziki aitzinatua bazen gizonen alfabetakuntza (osoa), anitzez apalago zen emazteena, hirian ere bai (neurri tikiagoan bazen ere). Konpara, adibidez, Baiona, Donibane Lohizun eta Paueko datuak : Baionan gizonetan 66,8k siñatzen dute eta emazteetan $\% 40,6 \mathrm{k}$, Donibane Lohizunen gizonetan $\% 37,8 \mathrm{k}$ izenpetzen dute, eta emazteetan $27,5 \mathrm{ek}$; aldiz, Pauen gizonetan \% 71,3k badakite siñatzen, eta emazteetan \% 27,8k. Halere, Euskal Herrian ere ez dira oro berdin ; ikus, adibidez, zer aldea den puntu horretan Donapaleuren eta Donibane Garaziren artean. Gizonetan portzentaia bertsuak ditugularik 1777-1785 urteetako ezkonlagunen izenpetzeetan ( $\%$ 48,2 eta $\%$ 46,6), emazteetan arras desberdinak dira : \% 7,1 eta \% 33,3; (ik. Pontet-Fourmigué $1990: 537$ ).

19. D. J. Garatek berak 1808an Savary-ri eginikako txostenean aipatzen du euskaldunen egoera eskolatzeari buruz, dioela : Avant la Révolution, des deux côtés des Pyrénées, tous les Basques, quoique très ignorants, savaient presque tous lire et écrire ; s'ils ont perdu cette instruction élémentaire, ils pourraient bientôt la reprendre, et toutes les connaissances d'hydrographie nécessaires au pilotage, souvent très utiles au matelots, il faudrait les leur donner en basque (ik. Duhart 1994, 2: 119) Garat, Iraultza denboran Hezkuntza ministroa izan bazen, eta haren gerizapean sortu baziren geroztik hain garrantzi handia izan duten Frantziako eskola normalak, zen bezalakoa zen, eta ez bide da horko aipua hitzez hitz hartzekoa, are gutiago mugaz hegoaldeko egoeraz ari denean. Halere, haren erranak, gauzen edertzeko nahikeria alde batetik emanez ere, zerbait adierazten duke : jendeak arras ezjakinak izan arren (très ignorants dio), anitzek bazekiketen irakurtzen, beren mintzairan bederen. Ez, segurenaz ere kasi denek, dioen bezala (gizo- 
nezkoak bakarrik gogoan izanik hain segur garai hartan), baina bai parte adierazgarri batek. Ohargarria da Garatentzat euskaraz egitekoa dela itsas gaietako irakaskintza teknikoa.

20. Horrela Donibane Lohizunen Derratxou izeneko bat, errejent gisa aritzeko aurkeztur zen, hartaz hauxe errana izan baitzen : qu'il ne connaissait pas l'orthographe, qu'il était faible en calcul, mais qu'il a été jugé en état d'enseigner à lire et à écrire aux enfants. (Aipua G. Pialloux-ek ematen du, Saint Jean de Luz liburuan, II, taldelana, $1994: 157$ ).

21. Lan hori Urquijo funtsean, Donostiako Koldo Mitxelena Kulturgunean, aurki daiteke, nahiz ikusi ahal izan dugun mikrofilman bederen ez den ageri Beaumont delakoaren siñadura. Hitz batez anonimo gisa agertzen da argazki hartan liburuxka.

22. Jatorriko irarlanaren orrialdeak kortxeten artean ematen ditut usaian bezala. Testuan zuzenketak egiten direnean, forma zuzenduaren ondoan ematen dugu jatorrikoa, kortxeten artean. 


\section{Bibliografia}

Ariès, P. 1960. L'enfant et la vie familiale sous l'Ancien Régime, argitalpen berria, 1973, Le Seuil, Paris.

Belapeyre, A. 1696. Catechima laburra eta Jesus-Christ goure Ginco Jaunaren eçagutçia, salvatu içateco, fac-simileko argitalpena eta J.-L. Davanten edizioa kritikoa, Euskaltzaindia, Bilbo, 1983. Ikus halaber P. Agirreren doktore tesia, EHU, 1996.

Butel, P. \& Mandon, G. 1977. "Alphabétisation et scolarisation en Aquitaine », in Furet \& Uzouf (zuzend.), Lire et écrire. L'alphabétisation des Français de Calvin à Jules Ferry, 07-41.

Castagnet, V. 1977. "Une dynastie d'évêques au XVIII siècle : les Révol et Montillet », Bulletin de la Société des Sciences, Lettres et Arts de Bayonne, 69-98.

Croix, A. \& Quéniart, J. 1998. Histoire de culturelle de la France. De la Renaissance à l'aube des lumières: J.-P. Roux eta J.-F. Sirinelli-ren zuzendaritzapean egin obrako bigarren liburukia, Le Seuil, Paris.

Darrobers, J.-N. 1994. “ Saint-Jean-de-Luz au XVIII ${ }^{e}$ siècle » in Saint Jean de Luz, II, Ekaina, Donibane Lohizune

Duhart, M. 1994. Dominique Joseph Garat (1749-1833), 2 lib., Bulletin de la Sociéte des Sciences, Letires. et Arts de Bayonne delakoaren separatak, Baiona.

M. Fleury \& S. Valmary, 1957. «Les progrès de l'instruction élímentuire de Louis XIV à Napoléon III d'après l'enquête de L. Maggiolo (1877-1879) ", Population (janviir-inars).

Furet, F. \& Ozouf, J. (zuzend.). 1977. Lire et écrire. L'alphabétisation des Françats de Calvin à Jules Ferry, 2 lib. Éditions de Minuit. Paris.

Furct. F. ¿ Sachs, W. 1974. « La croissunce de l'alphabétisation en France », Annales en Sciences sociales, 3

Haristoy, Abbé. 1890-1891. "Relevé des procès-verbaux des visites pastorales de VN. SS. De Beauvau et de Bellefont, évêques de Bayonne ", Bulletin de la Socièté des. Sciences, Luttres et Arts de Pau, 0 I-45

Hourmat, P. 1986. Histoire de Bayonne, Société des Lcicnces, Luttres et Arts du Bayonne, Baiona.

Julia, D. 1997. "Lectures et Contre-Réforme », in G. Cavallo \& R. Chartier, Histoire de la lecture dans le monde occidental, Le Scuil, Paris, 277-314.

Lafourcade, M. 1978. Les contrats de mariage en Labourd sous le règne de Louis XVI. Elude juridique et sociologique, Doktore tesia, Bordele I, 3 lib.

Muchenbled, R. 1990. Société, cultures mientulitis dans la France moderne, tVle-XVITe siècle, Colin, Paris.

Nogaret, J. 1925. Saint Jean de Luz des origines à nos jours, Baiona.

Pontet-Fourmigué, J. 1990. Bayonne, un destin de ville roycnne à l'époque moderne, J\&D éditions, Miarritze.

Pontut. J. 1996. "Compte rendu du mémoire de maitrise en histoire d'Anne Delpeuch : Elude démographique d'unc société coutumière: Ustaritz de 1745 à 1850. \%, Lapurdum, 1, 229-233.

Poussou, J.-P. 1977. «Recherches sur l'alphabétisation de I'Aquitaine au XVIII siècle », in Furet \& Ozouf (zuzend.), 295-347.

Sérurier, M. le Vicomte de - (1873-1874) : « De l'instruction primaire dans la région des Pyrénées occidentales et spécialement en Béarn depuis la fin du XIV siècle jusqu'en 1789 », Bulletin de la Société des Sciences, Lettres et Arts de Pau, Pau, 224-282

Soulice, !. 1872. "Statistigne de l'ignorance dans le département des Basses-Pyrénées », Bulletin de la Société des Scionces, Lettres et Arts de Put. Pau, 4153.

Soulice, L. 1880. « Notes pour servir à l'histoire de l'instruction primaire dans les Basses-Pyrénées. 13851880 », Bulletin de la Suciété des Sciences, Lettre's et Arts de Put. Pulu. 01-64.

Taldelana. 1994. Saint-Jeun-de-Luz, bigarren lib.. Fkaina, Donibane [ ohizun.

Vinson. J. 1891 \&: 1898. Bibliographie du la langue basque, I \& II, ASJUren argitalpena liburu bakarrean, 1984, Gipuzkoako Aldundia, Dono:tia. 


\section{Résumé}

L'article (dont le titre peut se traduire : L'instruction en langue basque : un petit livre scolaire datant de la période révolutionnaire, dans le prolongement de l'enseignement des petites écoles) se situe dans le cadre d'une recherche plus générale sur les conditions de la formation d'un lectorat en langue basque aux $\mathrm{XVII}^{\circ}$ et XVIII' siècle. Il est consacré d'une part à une présentation de l'enseignement populaire dans les petites écoles de Basse-Navarre, Labourd et Soule, d'autre part, à l'édition d'un texte imprimé sans date, mais remontant probablement aux toutes dernières années du XVIII ${ }^{e}$ siècle, et qui représente le premier opuscule scolaire connu rédigé en langue basque, en dehors des catéchismes.

Cet imprimé, décrit par Vinson dans sa bibliographie, mais dont le texte n'avait pas été republié, est surtout intéressant par le reflet qu'il nous donne de ce qu'a pu être l'enseignement populaire dans les provinces basques septentrionales jusqu'au XIX ${ }^{e}$ siècle. Bien que relativement tardif et contenant donc des éléments novateurs par rapport à ce que l'on peut supposer de l'enseignement des petites écoles dans les années précédant la Révolution, il demeure dans cette tradition en particulier dans sa forme, puisqu'il est fondé comme les catéchismes sur un patron questions-réponses, et qu'il est rédigé en basque.

Le livret comprend deux textes ; deux séries de questions-réponses (chacune ayant son titre), nettement siéparées, car dissemblables dans leur contenu, malgré certains points traités dans les deux parties. Le premier correspond à un livre de culture religieuse (pas un catéchisme); le second plutôt à un livre d'instruction générale (histoire, géographie, références culturelles élémentaires).

L'enseignement des petites écoles a été peu évoqué jusqu'ici dans la littérature relative au Pays Basque, alors que c'est sans doute sur lui qu'a reposé durant environ deux siècles la littérature d'expression basque dans les milieux populaires. On peut en effet supposer que c'est dans ce cadre que s'est formé un lectorat bascophone, souvent peu ou pas du tout lettré, mais susceptible d'accéder à une telle littérature, principalement fondée sur l'édification religieuse, et largement constituée de rééditions.

Les principales sources regardant ces écoles, et exploitées dans l'article, sont constituées par les ordonnances d'administration religieuse publiées par Belapeyre en tête de son catéchisme souletin de 1696, et les comptes-rendus des visites pastorales des évêques, tels qu'ils ont été réalisés au siècle dernier par Sérurier (1873-1874) et, surtout, Haristoy (1890-1891). Divers travaux relatifs aux conditions de l'enseignement de la lecture et de l'écriture en France (Aries 1960, Furet et Ozouf 1977, Muchenbled 1990, Croix et Quiénart 1998), et singulièrement en Aquitaine (Butel et Mandon 1977, Poussou 1977) à cette époque permettent de bien situer cet enseignement dans un cadre plus général, où l'on constate, à côté de l'enseignement disons classique, l'existence d'une scolarisation I) pouvant être limitée à la lecture, II) largement soumise au contrôle du clergé car associée à l'enseignement du catéchisme, III) recourant essentiellement à la langue vernaculaire comme langue de lecture, IV) mise en œuvre par un personnel peu qualifié et certainement mal rétribué, malgré le caractère souvent public ou semi-public de ces écoles, v) et faisant apparaître des oppositions fortes, d'ordre géographique (ville $v s$ campagne), sociale (petite bourgeoisie $v s$ artisans vs paysans) et sexuelle (enseignement masculin vs enseignement féminin). 